\title{
EVALUASI KINERJA SEBAGAI LANGKAH AWAL UNTUK PERUMUSAN STRATEGI CV. RUI INTI COORPORATION
}

\author{
Ansir Launtu \\ Dosen Tetap Yayasan STIEM Bongaya - YPBUP Jl. Letjend Mappaodang No. 28 Makassar \\ Email : anslau08@yahoo.com
}

\begin{abstract}
Performance evaluation is very important to be done, since it's good for giving feed back to company about their goal achievement which have been planned. Also, it can be used as an input to formulate the company strategy in coming periode. Performance measurement is done as an early step to improve CV. Rui Inti. The key performance indicators was formulated by four Balanced Scorecard perspective approach that are customer, internal business processes, financial, learning and growth. The next step is analising the measurement result by using the SWOT method, as an input to build alternative strategies for the company. Result of measurement indicate that in January, $C V$. RUI INTI performance is generally good, but in Juni until September the company performance descend to fair position. Based on internal and eksternal company evaluation, the proposed strategy is grouped into two shares, that is defend and expand. Defensive strategi for examples, improve product quality, improve service quality to costumers, and training for the company internal improvement. Expanding strategy for examples, cooperating with some owners of agriculture farms to add raw material supply, product diversification and the promotion activities.
\end{abstract}

Keywords: Spare Parts, Service, Key Performance Indicators, Cognos Analytic Applications.

\begin{abstract}
Abstrak : Evaluasi kinerja sangat penting untuk dilakukan, karena itu baik untuk memberikan umpan balik kepada perusahaan tentang pencapaian tujuan mereka yang telah direncanakan. Selain itu, dapat digunakan sebagai masukan untuk merumuskan strategi perusahaan dalam periode mendatang. Pengukuran kinerja ini dilakukan sebagai langkah awal untuk meningkatkan CV. Rui Inti . Indikator kinerja utama dirumuskan oleh empat pendekatan perspektif Balanced Scorecard yang pelanggan, proses bisnis internal , keuangan, pembelajaran dan pertumbuhan. Langkah berikutnya adalah proses menganalisa hasil pengukuran dengan menggunakan metode SWOT, sebagai masukan untuk membangun strategi alternatif bagi perusahaan. Hasil pengukuran menunjukkan bahwa pada bulan Januari, kinerja CV. RUI INTI umumnya baik, tapi di Juni sampai September kinerja perusahaan turun ke posisi yang adil . Berdasarkan evaluasi internal perusahaan dan eksternal, strategi yang diusulkan dikelompokkan menjadi dua bagian, yaitu mempertahankan dan memperluas. Defensive strategi untuk contoh, meningkatkan kualitas produk, meningkatkan kualitas layanan kepada pelanggan, dan pelatihan untuk pembenahan internal perusahaan. Memperluas strategi untuk contoh, bekerja sama dengan beberapa pemilik peternakan pertanian untuk menambah pasokan bahan baku , diversifikasi produk dan kegiatan promosi .
\end{abstract}

Kata kunci : Suku Cadang, Service, Key Performance Indicator, Cognos Aplikasi Analytic.

Perkembangan dunia industri yang sangat pesat saat ini mengakibatkan munculnya kompetisi yang sangat ketat di antara para pelaku bisnis, baik yang bergerak di bidang manufaktur maupun jasa. Oleh karena 
itu para pelaku bisnis, tak peduli besar atau kecil perusahaan yang dimiliki, selain dituntut untuk memenuhi kebutuhan pelanggan juga dituntut untuk melakukan perbaikan yang terus menerus terhadap kinerja perusahaan.

Nurmianto,dkk. menyatakan bahwa kinerja merupakan hasil kerja yang dicapai seseorang atau kelompok dalam suatu organisasi dalam kurun waktu tertentu berdasarkan standar kerja yang telah ditetapkan. Pengukuran kinerja akan sangat membantu pihak manajemen dalam menetapkan tujuan perusahaan, mengalokasikan dan menentukan prioritas sumber daya serta memberi informasi kepada pihak manajemen untuk meninjau ulang ataupun mengganti kebijakan/program tertentu yang akan mendukung pencapaian tujuan perusahaan. Hal ini seperti yang diungkapkan oleh Hayward (1998) dalam Amaratunga, et.al. (2000), "if you cannot measure it, how can you improve it”.

Seperti di banyak negara sedang berkembang lainnya, sektor industri manufaktur di Indonesia didominasi oleh Industri Kecil Menengah (IKM) dan Industri Rumah Tangga (IRT), baik dalam jumlah unit maupun pangsa kesempatan kerja [Tambunan, 2000]. Jadi, walaupun ruang lingkup usahanya tidak terlalu besar, namun dalam perekonomian nasional industri ini memegang peranan penting karena memiliki prospek yang sangat menjanjikan untuk berkembang menjadi perusahaan yang lebih besar pada masa depan. Namun, pada saat ini berbagai IKM yang ada masih memiliki berbagai kelemahan terutama dalam bidang administrasi dan manajemen, begitu juga dengan CV. RUI INTI. Kelemahan tersebut jika tidak segera ditangani, akan sangat berpengaruh bagi keberlangsungan IKM yang bersangkutan.
CV. RUI INTI adalah salah satu IKM yang ada di Kota Enrekang. Pendirian perusahaan ini berawal dari sedikitnya industri yang memproduksi makanan ringan khas kota Enrekang, khususnya keripik dangke. Secara legal CV. RUI INTI berdiri pada tahun 2011 dengan dikeluarkannya Surat Izin Usaha Perdagangan, namun aktivitas produksinya telah dimulai sejak bulan Juni 2012.

Selama ini pihak manajemen CV. RUI INTI belum pernah melakukan pengukuran kinerja karena keterbatasan informasi dan sumber daya manusia, padahal evaluasi kinerja merupakan salah satu tahapan penting dalam manajemen perusahaan. Hal ini dapat menyebabkan CV. RUI INTI sebagai perusahaan yang berorientasi bisnis kehilangan pegangan dalam memaksimalkan pendapatannya. Oleh karena itu perlu dilakukan pengukuran kinerja perusahaan agar diketahui kondisi perusahaan saat ini secara keseluruhan sebagai dasar bagi perencanaan sekaligus penentuan kebijakan-kebijakan perusahaan untuk masa yang akan datang.

Istilah "evaluasi kinerja" berasal dari dua suku kata yaitu evaluasi dan kinerja. Evaluasi dapat didefinisikan sebagai suatu proses untuk menyediakan informasi tentang sejauh mana suatu kegiatan tertentu telah dicapai, apakah ada selisih di antara hasil tersebut dengan standar yang ada, serta bagaimana manfaat hasil yang dicapai bila dibandingkan dengan harapanharapan yang ingin diperoleh [Umar, 2003].

Sedangkan pengertian kinerja menurut Bernandin and Russell dalam Gomes (1995) adalah suatu hasil yang dicapai dari pekerjaan atau kegiatan tertentu selama periode waktu tertentu. Kinerja juga dapat diartikan sebagai hasil kerja yang dicapai seseorang atau kelompok dalam suatu organisasi dalam 
kurun waktu tertentu berdasarkan standar kerja yang telah ditetapkan [Nurmianto, dkk, 2000].

Evaluasi kinerja memiliki banyak manfaat dalam organisasi bisnis. Menurut Artley dan Stroh (2001), diantaranya adalah untuk :

1. Menetapkan tujuan dan standar perusahaan.

2. Mendeteksi dan memperbaiki kesalahan.

3. Memberikan penilaian mengenai efektivitas dan efisiensi seseorang, suatu program dan proses.

4. Menentukan apakah suatu organisasi bisnis berjalan sesuai visinya.

5. Memperbaiki komunikasi secara internal di antara sesama karyawan dan secara eksternal antara perusahaan dengan pelanggan dan para stakeholder.

6. Membantu menyelaraskan antara aktivitas dengan biaya yang dikeluarkan.

7. Menggambarkan hasil pengukuran untuk melihat kesesuaian antara kinerja dengan target.

\section{Konsep Balanced Scorecard}

Pengertian Balanced Scorecard

(BSC) bisa diperoleh dengan memisahkan suku kata balanced dan scorecard. Di mana balanced secara harfiah artinya seimbang dan scorecard berarti kartu skor. Scorecard adalah kartu yang digunakan untuk mencatat skor hasil kinerja seseorang dan/atau suatu kelompok, juga untuk mencatat rencana skor yang hendak diwujudkan. Selanjutnya, seseorang dan/atau kelompok ini akan dievaluasi kinerjanya dengan membandingkan antara apa yang telah dikerjakan dengan apa yang telah direncanakan. Sementara itu, balanced adalah bahwa kinerja seseorang atau kelompok tertentu akan diukur secara berimbang antara sisi internal dan eksternal perusahaan, dan berimbang pula antara perspektif proses dan orang [Umar, 2002].

\section{Empat Perspektif Balanced Scorecard Balanced Scorecard memberikan}

kerangka kerja dengan empat perspektif yang merupakan perbaikan terhadap pengukuran kinerja tradisional yang hanya menitikberatkan pada perspektif finansial saja. Menurut Artley dan Stroh (2001), keempat perspektif tersebut adalah :

1. Perspektif finansial - Apakah tujuan strategis finansial perusahaan?

2. Perspektif pelanggan - Apakah yang harus dilakukan terhadap para pelanggan untuk mencapai kesuksesan finansial ?

3. Perspektif proses bisnis internal Proses bisnis mana yang paling mempengaruhi kepuasan pelanggan ?

4. Perspektif pertumbuhan dan pembelajaran - Perbaikan apa yang harus dilakukan untuk meningkatkan kepuasan pelanggan?

Analisis SWOT Sebagai Alat Formulasi Strategi

Dalam melakukan analisis SWOT (Strength, Weakness, Opportunity, Threat), pihak perusahaan harus mampu memahami lingkungan eksternal dan internal perusahaan dengan baik. Dengan demikian perusahaan dapat memaksimalkan peluang dan kekuatan serta meminimalkan kelemahan dan ancaman yang dimiliki perusahaan. Keempat kombinasi faktor -faktor tersebut dapat dilihat pada Tabel 1 . 
Tabel 1. Kombinasi faktor internal dan eksternal perusahaan

\begin{tabular}{|c|c|c|}
\hline $\begin{array}{c}\text { Faktor-Faktor } \\
\text { Organisasi }\end{array}$ & $\begin{array}{c}\text { Kekuatan } \\
\text { (Strength) }\end{array}$ & $\begin{array}{c}\text { Kelemahan } \\
\text { (Weakness) }\end{array}$ \\
\hline $\begin{array}{c}\text { Peluang } \\
\text { (Opportunity) }\end{array}$ & $\begin{array}{c}\text { Maxi-Maxi } \\
\text { (Strength/Oppprtunity) } \\
\text { Ciptakan strategi yang menggunakan } \\
\text { kekuatan untuk memanfaatkan peluang }\end{array}$ & $\begin{array}{c}\text { Mini-Maxi } \\
\text { (Weakness/Oppprtunity) } \\
\text { Ciptakan strategi yang meminimalkan } \\
\text { kelemahan untuk memanfaatkan peluang }\end{array}$ \\
\hline $\begin{array}{c}\text { Ancaman } \\
\text { (Threat) }\end{array}$ & $\begin{array}{c}\text { Maxi-Mini } \\
\text { (Strength/Threat) }\end{array}$ & $\begin{array}{c}\text { Mini-Mini } \\
\text { (Weakness/Threat) }\end{array}$ \\
& $\begin{array}{c}\text { Ciptakan strategi yang menggunakan } \\
\text { kekuatan untuk mengatasi ancaman }\end{array}$ & $\begin{array}{l}\text { Ciptakan strategi yang meminimalkan } \\
\text { kelemahan dan menghindari ancaman }\end{array}$ \\
\hline [Sumber : Aryo, dkk] & & \\
\hline
\end{tabular}

\section{METODE}

Tahap-tahap penelitian yang dilakukan dapat dilihat pada Gambar 1 berikut ini.

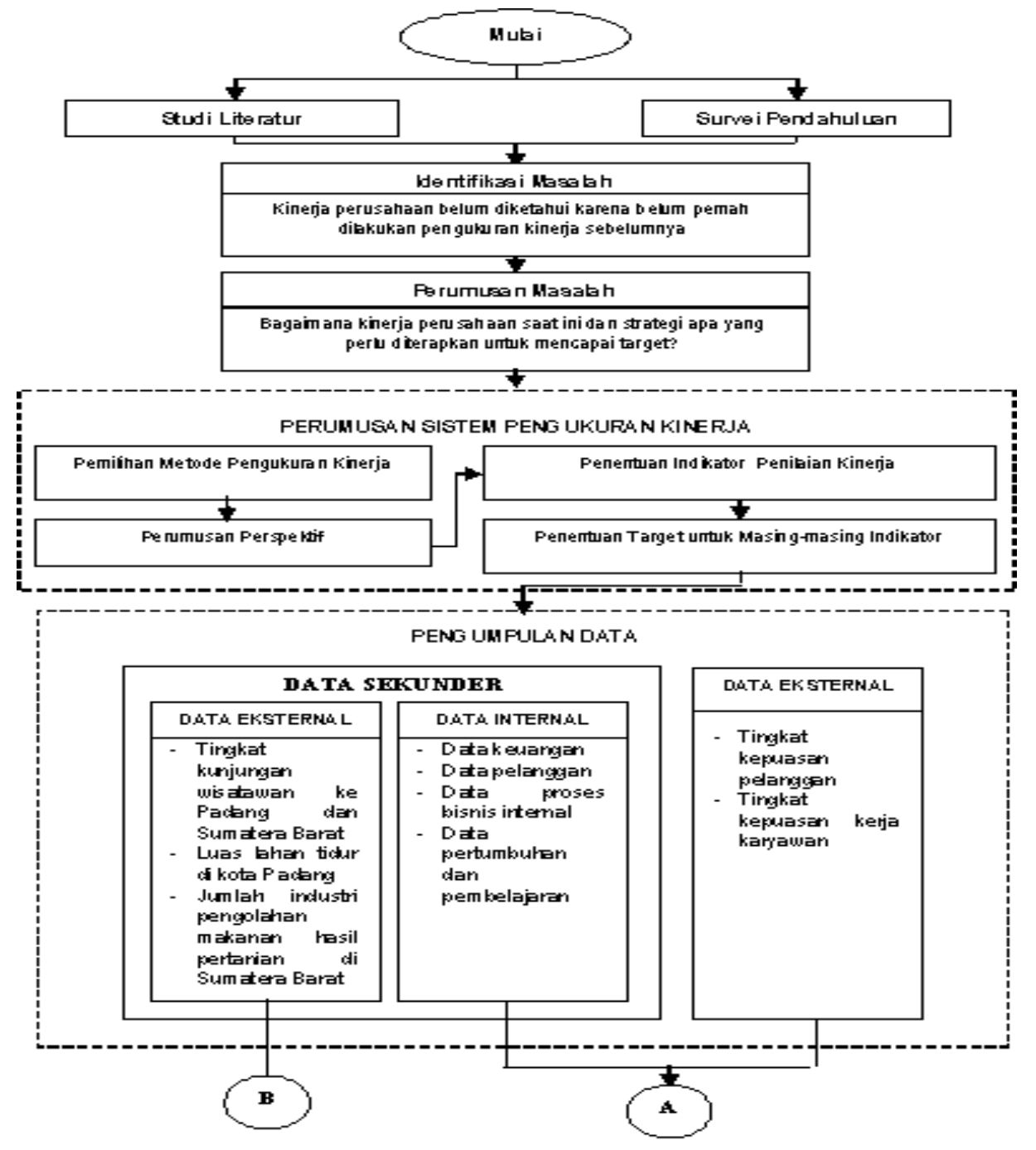


HASIL DAN PEMBAHASAN

\section{Hasil Pengolahan Data Sekunder}

\section{Perspektif Keuangan}

Dari sudut pandang keuangan, keberhasilan perusahaan dapat diukur dari empat hal yaitu profitabilitas, solvabilitas, likuiditas keuangan dan efisiensi pengelolaan harta [Sutojo, 2004]:

Rasio keuangan utama yang digunakan sebagai tolak ukur profitabilitas perusahaan adalah marjin laba kotor (gross profit margin), laba atas penjualan (profit on sales), laba atas investasi dana (return on investment), pertumbuhan penjualan dan laba atas modal sendiri ( return on equity).

Tingkat solvabilitas perusahaan dapat diukur dengan membandingkan antara jumlah utang dan harta perusahaan (total debts to assets), serta jumlah utang jangka panjang dan modal sendiri (long term debts to networth).

Tingkat likuiditas perusahaan ini dapat diukur dengan membandingkan antara jumlah harta lancar dan hutang lancar (current ratio).

Rasio keuangan yang biasa digunakan untuk mengukur kemampuan manajemen perusahaan untuk mengelola harta secara efisien adalah perbandingan antara jumlah hasil penjualan bersih dan harta (assets turn over), dan perbandingan antara jumlah saldo piutang dagang dengan hasil penjualan bersih (average collection period). Hasil pengukuran perspektif keuangan dapat dilihat pada Tabel 2.

Tabel 2. Hasil pengukuran indikator kinerja untuk perspektif keuangan

\begin{tabular}{|c|c|c|c|c|c|c|}
\hline \multirow{2}{*}{ No. } & \multirow{2}{*}{ Indikator } & \multicolumn{5}{|c|}{ Bulan } \\
\hline & & $\mathrm{Jan}$ & Feb & Mar & Apr & Mei \\
\hline & PROFITABIITAS & & & & & \\
\hline 1 & Marjin laba kotor $(\%)$ & 49,25 & 35,36 & 59,95 & 52,75 & 51,26 \\
\hline 2 & Rasio laba atas penjualan (\%) & 38,40 & 25,10 & 36,17 & 38,46 & 32,63 \\
\hline 3 & Rasio laba atas investasi dana $(\%)$ & 9,05 & 4,70 & 5,30 & 7,40 & 5,76 \\
\hline 4 & Pertumbuhan penjualan (\%) & & $-18,13$ & $-20,51$ & 30,58 & $-6,06$ \\
\hline \multirow[t]{2}{*}{$s$} & Rasio laba atas modal sendiri (\%) & 15,54 & 8,43 & 8,96 & 12,42 & 9,60 \\
\hline & SOLVABILTTAS & & & & & \\
\hline 1 & Rasio hutang terhadap harta (\%) & 38,32 & 42,23 & 38,80 & 37,59 & 37,78 \\
\hline \multirow[t]{2}{*}{2} & $\begin{array}{l}\text { Rasio hutang jangka panjang tl} \Psi \text { modal } \\
\text { sendiri (\%) }\end{array}$ & 23,55 & 23,54 & 21,56 & 21,22 & 20,29 \\
\hline & LIKUIDITAS KEUANGAN & & & & & \\
\hline \multirow[t]{2}{*}{1} & Rasio harta lancar terhadap hutang lancar & 1,10 & 0,94 & 1,11 & 1,20 & 1,21 \\
\hline & EFISIENSI PENG. HARTA & & & & & \\
\hline 1 & Rasio penjualan bersih terhadap hanta (\%) & 22 & 18 & 14 & 18 & 17 \\
\hline 2 & Jangka waktu penagikam pintame (hari) & 38 & 51 & 75 & 54 & 65 \\
\hline 3 & Efeltivitas penagihan pintang (\%) & 81,30 & 58,26 & 41,30 & 46,91 & 47,94 \\
\hline 4. & Perputaran persediaan & 2,41 & 2,97 & 1,24 & 1,60 & 1,49 \\
\hline
\end{tabular}

\section{Perspektif Pelanggan}

Perspektif pelanggan diukur dengan menggunakan dua jenis indikator yaitu yang bersifat kuantitatif dan kualitatif : 
Indikator yang bersifat kuantitatif antara lain adalah persentase penambahan pelanggan baru (akuisisi pelanggan), persentase barang sisa (produk yang dikembalikan oleh pelanggan) dan persentase penjualan per pelanggan.

Indikator yang bersifat kualitatif digunakan untuk mengukur kualitas produk dan kualitas pelayanan secara lebih detail. Untuk pengukuran kualitas produk dilakukan dengan mengembangkan model sikap dan perilaku Fishbein, sedangkan pengukuran kualitas pelayanan dilakukan dengan mengembangkan dimensi kualitas jasa oleh Zeithaml, et.al. [Umar, 2003]. Setiap atribut atau indikator disesuaikan dengan karakteristik CV. RUI INTI

Tabel 3. Hasil pengukuran indikator kinerja untuk perspektif pelanggan

\begin{tabular}{|c|l|c|c|c|c|c|}
\hline \multirow{2}{*}{ No. } & \multicolumn{2}{|c|}{ Indikator } & \multicolumn{5}{|c|}{ Bulan } \\
\cline { 3 - 7 } & & Jan & Feb & Mar & Apr & Mei \\
\hline 1 & $\begin{array}{l}\text { Persertase penambahan } \\
\text { pelangzan banu (\%) }\end{array}$ & & & 11,88 & 16,94 & 4,35 \\
\hline 2 & Persertase pelangzan aktif (\%) & & & $45,87 \%$ & $30,05 \%$ & $60,87 \%$ \\
\hline 3 & $\begin{array}{l}\text { Rasio penjualankanvas per } \\
\text { pelangan (Rq/Pelangzan) }\end{array}$ & 450.189 & 342.980 & 223.474 & 294.674 & 254.946 \\
\hline
\end{tabular}

\section{Perspektif Proses Bisnis Internal}

Perspektif proses bisnis internal diukur dengan beberapa indikator yang mengacu kepada aktivitas-aktivitas yang mendukung kegiatan operasional CV. RUI INTI. Indikator-indikator tersebut antara lain adalah :

1. Produktivitas bahan baku utama

2. Persentase pencapaian target produksi
3. Persentase kehilangan produk oleh tenaga penjualan/kanvas

4. Persentase barang kembali/rusak oleh pelanggan

5. Kontinuitas bahan baku

6. Kuantitas bahan baku

Hasil pengukuran perspektif keuangan dapat dilihat pada Tabel 4 Tabel 6.

Tabel 4. Hasil pengukuran produktivitas bahan baku,kontinuitas dan kuantitas pasokan bahan baku

\begin{tabular}{|l|c|c|c|c|c|}
\hline \multirow{2}{*}{ Indikator } & \multicolumn{5}{|c|}{ Bulan } \\
\cline { 2 - 6 } & Jan & Feb & Mar & Apr & Mei \\
\hline Produktiritas bahanbaku & 1,55 & 1,57 & 1,08 & 1,59 & 1,30 \\
\hline Kortirnitas bahm baku (\%) & 84,62 & 79,17 & 74,07 & 53,85 & 92,31 \\
\hline $\begin{array}{l}\text { Kuantitas baham baku (krg per } \\
\text { hari) }\end{array}$ & 20 & 21 & 12 & 16 & 17 \\
\hline
\end{tabular}


Tabel 5. Hasil pengukuran indikator persentase barang hilang

\begin{tabular}{|c|c|c|c|c|c|}
\hline \multirow{2}{*}{ Jenis Produlk } & \multicolumn{5}{|c|}{ Persentase Baramg Hilang (\%) } \\
\hline & $\operatorname{Tan}$ & Feb & Mar & Apr & Mei \\
\hline KPMI & 0,00 & 0,00 & 1,37 & 5,50 & 5,00 \\
\hline KBMT & 0,00 & 0,00 & 0,00 & 0,00 & 0,00 \\
\hline KFIMI & 0,00 & 0,00 & 0,00 & 0,00 & 43,33 \\
\hline KP.P & 0,00 & 0,20 & 4,79 & 0,00 & 0,19 \\
\hline KKF & 0,00 & 0,00 & 4,66 & 0,00 & 0,10 \\
\hline KKP.P & 0,00 & 3,72 & $0, \infty$ & 0,00 & 0,00 \\
\hline KF & 0,00 & 1,58 & 0,00 & 2,88 & 1,68 \\
\hline KFI & 0,00 & 0,00 & 0,00 & 0,00 & 0,00 \\
\hline KIB & 0,00 & 0,00 & 4,39 & 1,17 & 1,54 \\
\hline KIK & 0,00 & 0,00 & 0,56 & 7,69 & 3,57 \\
\hline $\mathrm{SB}$ & 8,33 & 4,43 & 0,00 & 0,00 & 3,50 \\
\hline SK & 2,98 & 0,90 & 1,47 & 0,00 & 0,00 \\
\hline TJ & 0,00 & 18,21 & 3,88 & 0,00 & 5,44 \\
\hline $\mathrm{cc}$ & 0,00 & 0,00 & $0, \infty$ & 0,00 & 0,00 \\
\hline A & 0,00 & 1,66 & 16,77 & 16,77 & 1,05 \\
\hline K.Pls & 0,00 & 0,00 & 11,42 & 11,42 & 6,88 \\
\hline K.Kstk & 28,68 & 10,21 & 0,00 & 0,00 & 0,00 \\
\hline $\mathrm{J} 1 / 2$ & 0,00 & 0,00 & 0,00 & 0,00 & 0,00 \\
\hline $\mathrm{KC} 1,5$ & 0,00 & 0,00 & 0,10 & 0,10 & $0, \infty 0$ \\
\hline KC SO0 & 0,00 & 0,00 & 0,00 & 0,00 & 0,00 \\
\hline Rata-rata & 13,33 & 5,11 & 4,94 & 4,31 & 6,57 \\
\hline
\end{tabular}

Tabel 6. Hasil pengukuran indikator persentase barang kembali

\begin{tabular}{|c|c|c|c|c|c|}
\hline \multirow{2}{*}{ Jenis Produk } & \multicolumn{5}{|c|}{ Persentase Barang Kembali (\%) } \\
\hline & $\operatorname{Jan}$ & Feb & Mar & Apr & Mei \\
\hline KPM & $0, \mathbf{0 0}$ & 0,22 & 0,01 & 0,02 & 0,02 \\
\hline KBM & $0, \mathbf{0 0}$ & $0, \mathbf{0 0}$ & $0, \mathbf{0 0}$ & $0, \mathbf{0 0}$ & 0,00 \\
\hline KKBM & 0,00 & 0,00 & $0, \infty 0$ & $0, \infty$ & 0,00 \\
\hline KPP & 2,60 & 0,01 & 0,05 & 0,20 & 0,14 \\
\hline KKP & 2,77 & 0,03 & 0,04 & 0,06 & 0,04 \\
\hline KKP P & 7,55 & 0,10 & $0, \infty 0$ & 0,12 & 0,22 \\
\hline KB & 0,25 & 0,01 & $0, \mathbf{0 0}$ & 0,01 & 0,00 \\
\hline KKB & $0, \mathbf{0 0}$ & 0,01 & $0, \infty 0$ & $0, \mathbf{\infty}$ & 0,08 \\
\hline KLB & $3, \infty 0$ & 0,02 & 0,05 & 0,05 & 0,03 \\
\hline KLK & 1,97 & 0,02 & 0,04 & 0,02 & 0,01 \\
\hline SB & 4,91 & 0,04 & 0,04 & 0,06 & 0,03 \\
\hline SK & 5,21 & 0,03 & 0,05 & 0,05 & 0,02 \\
\hline TJ & 3,78 & 0,02 & 0,02 & 0,05 & 0,01 \\
\hline $\mathrm{CC}$ & 13,50 & 0,25 & 0,06 & 0,04 & 0,01 \\
\hline A & 0,00 & $0, \infty 0$ & 0,01 & $0, \infty 0$ & 0,00 \\
\hline K.Pls & 1,27 & 0,08 & 0,08 & 0,01 & 0,02 \\
\hline K.K.tk & 17,50 & 0,18 & 0,02 & $0, \infty 0$ & 0,02 \\
\hline $\mathrm{J} 1 / 2$ & 0,00 & $0, \infty 0$ & $0, \infty 0$ & $0, \mathbf{0 0}$ & 0,00 \\
\hline J $1 / 4$ & 0,00 & 0,00 & $0, \infty 0$ & $0, \infty$ & 0,00 \\
\hline $\mathrm{J} 2$ & 0,00 & $0, \infty 0$ & $0, \infty 0$ & $0, \infty 0$ & 0,00 \\
\hline $\mathrm{KC} 1,5$ & 0,34 & $0, \mathbf{0 0}$ & 0,03 & 0,02 & 0,00 \\
\hline $\mathrm{KC} \mathrm{SO0}$ & $0, \infty$ & $0, \infty 0$ & 0,00 & $0, \infty$ & 0,00 \\
\hline Rata-rata & 4,62 & 6,93 & 3,88 & 5,32 & 4,37 \\
\hline
\end{tabular}




\section{Perspektif Pertumbuhan dan Pembelajaran}

Indikator yang digunakan untuk mengukur perspektif pertumbuhan dan pembelajaran ini antara lain adalah : tingkat perputaran karyawan, absensi karyawan, produktivitas karyawan produksi dan penjualan, serta tingkat kepuasan karayawan.

Khusus untuk indikator kepuasan kerja karyawan diukur dengan melakukan survai terhadap seluruh karyawan tetap CV. RUI INTI. InPidropektif Pertumbuh kepuasan kerja yang digunakan dikembangkan dari faktor-faktor kepuasan kerja yang dirangkum oleh As'ad (2003).

Hasil pengukuran perspektif keuangan dapat dilihat pada Tabel 7. Hasil pengukuran perspektif keuangan dapat dilihat pada Tabel 3 .

Tabel 7. Hasil pengukuran indikator kinerja untuk perspektif pertumbuhan dan pembelajaran

\begin{tabular}{|c|c|c|c|c|c|c|}
\hline \multirow{2}{*}{ No. } & \multirow{2}{*}{ Indikator } & \multicolumn{5}{|c|}{ Bulan } \\
\hline & & Jan & Feb & Mar & Apr & MLi \\
\hline 1 & $\begin{array}{l}\text { Tingkat perputaran } \\
\text { karyawan }(\%)\end{array}$ & 0 & 0 & 6 & 0 & 0 \\
\hline 2 & $\begin{array}{l}\text { Absensi karyawan } \\
(\%)\end{array}$ & $*$ & 7 & $*$ & $*$ & 3 \\
\hline 3 & $\begin{array}{l}\text { Produktivitas } \\
\text { karyawan } \\
\text { bag. produksi ( } \mathrm{Rp} \\
\text { per orang) }\end{array}$ & 263.273 & 281.698 & 178.194 & 187.217 & 212.640 \\
\hline 4 & $\begin{array}{l}\text { Produktivitas } \\
\text { karyawan penjualan } \\
\text { (Rp per orang) }\end{array}$ & 21.204 .582 & 17.360 .608 & 13.799 .831 & 18.019 .338 & 16.927 .000 \\
\hline
\end{tabular}

Hasil Pengolahan Data Primer

Pengolahan data yang menggunakan data primer dilakukan untuk mengukur tingkat kepuasan pelanggan dan tingkat kepuasan kerja karyawan.

\section{Uji Validitas}

Pengujian validitas kuesioner pada penelitian ini menggunakan teknik korelasii produk momen. Nilai koefisien korelasi yang didapatkan dibandingkan dengan koefisien korelasi (r) tabel pada taraf signifikan 5\%. Jika $r_{\text {hitung }}>r_{\text {tabel, }}$, maka item pertanyaan dinyatakan valid. Rangkuman hasil uji validitas ini dapat dilihat pada Tabel 8 dan Tabel 9.

Tabel 8. Rekapitulasi nilai r pengujian validitas kuesioner kepuasan pelanggan

\begin{tabular}{|c|c|c|}
\hline No. Butix & $\boldsymbol{x}_{\text {hinime }}$ & Hasil Uji Validitas \\
\hline 1 & 0,573 & Valid \\
\hline 2 & 0,485 & Valid \\
\hline 3 & 0,493 & Valid \\
\hline 4 & 0,406 & Valid \\
\hline 5 & 0,589 & Walid \\
\hline 6 & 0,493 & Valid \\
\hline 7 & 0,809 & Valid \\
\hline 8 & 0,416 & Valid \\
\hline 9 & 0,402 & Walid \\
\hline 10 & 0,759 & Valid \\
\hline 11 & 0,426 & Valid \\
\hline 12 & 0,853 & Walid \\
\hline 13 & 0,433 & Valid \\
\hline 14 & 0,525 & Valid \\
\hline 15 & 0,502 & Valid \\
\hline 16 & 0,508 & Valid \\
\hline 17 & 0,470 & Valid \\
\hline 18 & 0,535 & Valid \\
\hline 19 & 0,545 & Valid \\
\hline 20 & 0,462 & Valid \\
\hline
\end{tabular}


Tabel 9. Rekapitulasi nilai r pengujian validitas kuesioner kepuasan kerja karyawan

\begin{tabular}{|c|c|c|c|}
\hline No. Butir & $\mathbf{r}_{\text {L }}$ & $\mathrm{N}$ & Hasil Uji Validitas \\
\hline 1 & 0,578 & 17 & Valid \\
\hline 2 & 0,573 & 17 & Valid \\
\hline 3 & 0,585 & 17 & Valid \\
\hline 4 & 0,507 & 17 & Valid \\
\hline 5 & 0,580 & 17 & Valid \\
\hline 5 & 0,509 & 17 & Valid \\
\hline 7 & 0,637 & 17 & Valid \\
\hline 8 & 0,576 & 17 & Valid \\
\hline 9 & 0,554 & 17 & Valid \\
\hline 10 & 0,491 & 17 & Valid \\
\hline 11 & 0,507 & 17 & Valid \\
\hline 12 & 0,644 & 17 & Valid \\
\hline 13 & 0,597 & 17 & Valid \\
\hline 14 & 0,614 & 17 & Valid \\
\hline 15 & 0,581 & 17 & Valid \\
\hline 16 & 0,700 & 17 & Valid \\
\hline 17 & 0,633 & 17 & Valid \\
\hline 18 & 0,742 & 17 & Valid \\
\hline 19 & 0,584 & 12 & Valid \\
\hline 20 & 0,709 & 12 & Valid \\
\hline 21 & 0,590 & 12 & Valid \\
\hline 22 & 0,602 & 12 & Valid \\
\hline 23 & 0,527 & 17 & Valid \\
\hline 24 & 0,573 & 17 & Valid \\
\hline 25 & 0,280 & 17 & Tdk Valid \\
\hline (N $:$ 17, & & & \\
\hline
\end{tabular}

\section{Uji Reliabilitas}

Pada penelitian ini, uji reliabilitas kuesioner dilakukan dengan menggunakan metoda Alpha Cronbrach. Nilai koefisien keandalan yang mendekati 1 menyatakan kuesioner yang digunakan semakin handal. Jika nilai koefisien keandalan berada di atas 0,6 maka kuesioner tersebut sudah baik dalam mengukur gejala yang akan diukur. Rangkuman nilai koefisien keandalan dapat dilihat pada Tabel 10 dan Tabel 11.

Tabel 10. Hasil pengujian reliabilitas kuesioner kepuasan kerja yang dirasakan karyawan

\begin{tabular}{|l|c|c|c|}
\hline \multicolumn{1}{|c|}{ Dimensi } & Nilai Uji Reliabilitas & Nilai Alpha Mininum & Hasil Uji Reliabilitas \\
\hline PSIKOLOGIS & 0,8283 & 0,6 & Reliabel \\
\hline SOSIAL & 0,6494 & 0,6 & Reliabel \\
\hline FISIK (N=17) & 0,6234 & 0,6 & Reliabel \\
\hline FISIK (N=12) & 0,7057 & 0,6 & Reliabel \\
\hline FIHAKSIAL & 0,7631 & 0,6 & Reliabel \\
\hline
\end{tabular}

Tabel 11. Hasil pengujian reliabilitas kuesioner kepuasan kerja yang dirasakan karyawan

\begin{tabular}{|l|l|c|c|c|}
\hline \multicolumn{1}{|c|}{ Dimensi } & \multicolumn{1}{|c|}{ Variabel } & $\begin{array}{c}\text { Nilai Uji } \\
\text { Reliabilitas }\end{array}$ & $\begin{array}{c}\text { Nilai Alpha } \\
\text { Minimum }\end{array}$ & $\begin{array}{c}\text { Hasil Uji } \\
\text { Reliabilitas }\end{array}$ \\
\hline Kualitas Produk & & 0,7545 & 0,6 & Reliabel \\
\hline Kualitas Pelayanan & Reliability & 0,8354 & 0,6 & Reliabel \\
\hline & Responsiveness & 0,6984 & 0,6 & Reliabel \\
\hline & Assurance & 0,8856 & 0,6 & Reliabel \\
\hline & Empathy & 0,6058 & 0,6 & Reliabel \\
\hline
\end{tabular}

\section{Pengukuran Skor Tingkat Kepuasan Kerja Karyawan dan Kepuasan Pelanggan}

Setelah melakukan pengujian validitas dan reliabilitas terhadap kuesioner, langkah selanjutnya yang harus dilakukan dalam pengolahan data primer ini adalah mengukur skor tingkat kepuasan kerja karyawan dan kepuasan pelanggan. Tujuan dari pengukuran ini 
adalah untuk membandingkan antara harapan dan kenyataan yang dirasakan oleh karyawan dan pelanggan CV. RUI INTI. Dengan melakukan perbandingan, kita dapat memperoleh informasi bagian mana yang membutuhkan perbaikan atau peningkatan.

Berikut ini diuraikan kriteria nilai yang digunakan dalam kuesioner kepuasan kerja karyawan dan kepuasan pelanggan:

Nilai 4: sangat setuju, selalu, sangat penting, sangat menarik, sangat disukai, sangat tahan, sangat berpengaruh.

Tabel 12. Rekapitulasi skor kepuasan kerja yang dirasakan dan diharapkan karyawan

\begin{tabular}{|l|c|c|c|c|}
\hline \multirow{2}{*}{ Dimensi } & \multicolumn{2}{|c|}{ Kenyataan } & \multicolumn{2}{c|}{ Harapan } \\
\cline { 2 - 5 } & Skor & Persentase & Skor & Persentase \\
\hline PSIKOLOGIS & 3,1070 & $77,67 \%$ & 3,1604 & $79,01 \%$ \\
\hline SOSIAL & 2,8676 & $71,69 \%$ & 3,2794 & $81,99 \%$ \\
\hline FISIK & 3,1590 & $78,97 \%$ & 3,2815 & $82,04 \%$ \\
\hline FINAHSIAL & 2,7647 & $69,12 \%$ & 3,6765 & $91,91 \%$ \\
\hline \multicolumn{1}{|c|}{ Rata-Rata } & 2,9746 & $74,36 \%$ & 3,3495 & $83,74 \%$ \\
\hline
\end{tabular}

Tabel 13. Rekapitulasi skor kepuasan yang dirasakan dan diharapkan pelanggan

\begin{tabular}{|l|l|c|c|c|c|}
\hline \multirow{2}{*}{ Dimensi } & \multirow{2}{*}{ Variabel } & \multicolumn{2}{c|}{ Kenyatam } & \multicolumn{2}{c|}{ Harapam } \\
\cline { 3 - 6 } & & Skor & Persertase & Skor & Persertase \\
\hline KUALITAS PRODUK & & 2,9258 & $73,15 \%$ & 3,2540 & $81,35 \%$ \\
\hline $\begin{array}{l}\text { KUALTTAS } \\
\text { PELAYAHAN }\end{array}$ & Reliability & 3,5242 & $88,10 \%$ & 3,4113 & $85,28 \%$ \\
\hline & Responsiveness & 3,7849 & $94,62 \%$ & 3,2903 & $82,26 \%$ \\
\hline & Assurance & 3,6290 & $90,73 \%$ & 3,6129 & $90,32 \%$ \\
\hline & Empatiy & 3,1398 & $78,49 \%$ & 3,0430 & $76,08 \%$ \\
\hline & Rata-Rata & 3,3729 & $84,32 \%$ & 3,3223 & $83,06 \%$ \\
\hline
\end{tabular}

\section{Perbandingan antara skor kuesiner harapan dengan skor kuesioner aktual}

Perbandingan tingkat kepuasan kerja yang dirasakan dan diharapkan karyawan dilakukan dengan mencari selisih antara skor kepuasan kerja yang diharapkan dengan skor kepuasan kerja yang dirasakan. Apabila selisih yang diperoleh bernilai negatif, berarti skor kepuasan aktual lebih rendah daripada skor kepuasan harapan, dan sebaliknya. Sedangkan nilai nol menyatakan bahwa tidak terdapat kesenjangan antara skor
Nilai 3: setuju, seringkali, penting, menarik, sedang, cukup tahan, berpengaruh.

Nilai 2: kurang setuju, kadang-kadang, kurang penting, kurang menarik, kurang disukai, kurang tahan, kurang berpengaruh.

Nilai 1: tidak setuju, tidak pernah, tidak penting, tidak menarik, tidak disukai, tidak tahan, tidak berpengaruh.

Hasil rekapitulasi skor kuesioner karyawan dan pelanggan dapat dilihat pada Tabel 12 dan Tabel 13. 
Tabel 14. Tingkat kesenjangan antara kepuasan kerja yang dirasakan dan diharapkan karyawan

\begin{tabular}{|l|c|c|}
\hline \multirow{2}{*}{\multicolumn{1}{|c|}{ Dimensi }} & \multicolumn{2}{c|}{ Tingkat Kesenjangan } \\
\cline { 2 - 3 } & Skor & Persentase \\
\hline PSIKOLOGIS & $-0,0535$ & $-1,69 \%$ \\
\hline SOSIAL & $-0,4118$ & $-12,56 \%$ \\
\hline FISIK & $-0,1225$ & $-3,73 \%$ \\
\hline FIHAHSIAL & $-0,9118$ & $-24,80 \%$ \\
\hline Rata-Rata & $-0,3749$ & $-10,70 \%$ \\
\hline
\end{tabular}

Tabel 15. Tingkat kesenjangan antara kepuasan yang dirasakan dan diharapkan pelanggan

\begin{tabular}{|l|l|c|c|}
\hline \multirow{2}{*}{ Dimensi } & \multirow{2}{*}{ Variabel } & \multicolumn{2}{c|}{ Tirgkat Kesenjangan } \\
\cline { 3 - 4 } & & Skor & Persertase \\
\hline KUALTTAS PRODUK & & $-0,3282$ & $-10,09 \%$ \\
\hline KUALITAS PELAYAHAH & Reliability & 0,1129 & $3,31 \%$ \\
\hline & Responsiveness & 0,4946 & $15,03 \%$ \\
\hline & Assurance & 0,0161 & $0,45 \%$ \\
\hline & Enpathy & 0,0968 & $3,18 \%$ \\
\hline & Rata-Rata & 0,0506 & $1,52 \%$ \\
\hline
\end{tabular}

\section{Penetapan Target dan Skor Pencapaian Kinerja untuk Masing- Masing Indikator Kinerja CV. Rui Inti}

Sebelum melakukan penilaian terhadap kinerja CV.Rui Inti, terlebih dahulu harus ditetapkan target untuk masing-masing indikator. Target-target ini berfungsi sebagai tolok ukur kinerja yang menjadi dasar perbandingan dalam melakukan penilaian.

Tolok ukur terhadap indikator kinerja CV.Rui Inti terhadap perspektif keuangan disajikan dalam bentuk scorecard seperti terlihat pada Tabel 16.

\section{Scorecard untuk perspektif keuangan}

\begin{tabular}{|c|c|c|c|c|}
\hline No. & Indikator Kinerja & Target & Kriteria Penilaian & Skor \\
\hline \multirow{5}{*}{1} & \multirow{5}{*}{ Marjin Laba Kotor (MLK) } & \multirow{5}{*}{$\begin{array}{l}\text { MLK mencapai } \\
50 \%\end{array}$} & MLK $\geq 50 \%$ & 5 \\
\hline & & & $40 \% \leq \mathrm{MLK}<50 \%$ & 4 \\
\hline & & & $30 \% \leq \mathrm{MLK}<40 \%$ & 3 \\
\hline & & & $21 \% \leq \mathrm{MLK}<30 \%$ & 2 \\
\hline & & & MLK $<21 \%$ & 1 \\
\hline \multirow{5}{*}{2} & \multirow{5}{*}{ Laba atas Penjualan (LAP) } & \multirow{5}{*}{$\begin{array}{l}\text { LAP mencapai } \\
20 \%\end{array}$} & $L A P \geq 20 \%$ & 5 \\
\hline & & & $14 \% \leq \mathrm{LAP}<20 \%$ & 4 \\
\hline & & & $6 \% \leq \mathrm{LAP}<14 \%$ & 3 \\
\hline & & & $0 \% \leq \mathrm{LAP}<6 \%$ & 2 \\
\hline & & & $\mathrm{LAP}<0 \%$ & 1 \\
\hline \multirow{5}{*}{3} & \multirow{5}{*}{$\begin{array}{l}\text { Laba atas Investasi Dana } \\
\text { (LAID) }\end{array}$} & \multirow{5}{*}{$\begin{array}{l}\text { LAID mencapai } \\
7 \%\end{array}$} & LAID $\geq 7 \%$ & 5 \\
\hline & & & $5 \% \leq \mathrm{L}$ AID $<7 \%$ & 4 \\
\hline & & & $2 \% \leq \mathrm{LAID}<5 \%$ & 3 \\
\hline & & & $0 \% \leq$ LAID $<2 \%$ & 2 \\
\hline & & & LAID $<0 \%$ & 1 \\
\hline \multirow{5}{*}{4} & \multirow{5}{*}{ Pertumbuhan Penjualan (PP) } & \multirow{5}{*}{$\begin{array}{l}\text { PP mencapai } \\
5 \%\end{array}$} & $\mathrm{PP} \geq 5 \%$ & 5 \\
\hline & & & $3,50 \% \leq \mathrm{PP}<5 \%$ & 4 \\
\hline & & & $1,75 \% \leq \mathrm{PP}<3,50 \%$ & 3 \\
\hline & & & $0 \% \leq \mathrm{PP}<1,75 \%$ & 2 \\
\hline & & & $\mathrm{PP}<0 \%$ & 1 \\
\hline
\end{tabular}


Tabel 16. Scorecard untuk perspektif keuangan (lanjutan)

\begin{tabular}{|c|c|c|c|c|}
\hline Fo. & Indikator Kinerja & Target & Kriteria Perilaian & Skox \\
\hline \multirow{5}{*}{5} & \multirow{5}{*}{$\begin{array}{l}\text { Laba atas Modal Sendiri } \\
\text { (LAMS) }\end{array}$} & \multirow{5}{*}{$\begin{array}{l}\text { LAMS } \\
\text { mencapai } 11 \%\end{array}$} & LAMS $\geq 11 \%$ & 5 \\
\hline & & & $7,5 \% \leq \overline{L A M S}<11 \%$ & 4 \\
\hline & & & $3,75 \% \leq$ LAMS $\leq 7,5 \%$ & 3 \\
\hline & & & $0 \% \leq$ LAMS $\leq 3,75 \%$ & 2 \\
\hline & & & LAMS $\leq 0 \%$ & 1 \\
\hline \multirow{5}{*}{6} & \multirow{5}{*}{$\begin{array}{l}\text { Rasio Hutang terhadap Harta } \\
\text { (RHTH) }\end{array}$} & \multirow{5}{*}{$\begin{array}{l}\text { RHTH tidak } \\
\text { melebiki } 50 \%\end{array}$} & RHTH $\leq 50 \%$ & 5 \\
\hline & & & $50 \%<$ RHTH $\leq 65 \%$ & 4 \\
\hline & & & $65 \% \leq \mathrm{RHTH} \leq 85 \%$ & 3 \\
\hline & & & $85 \%=\mathrm{RHTH} \leq 100 \%$ & 2 \\
\hline & & & RHTH $=100 \%$ & 1 \\
\hline \multirow{5}{*}{7} & \multirow{5}{*}{$\begin{array}{l}\text { Rasio Hutang Janglka Panjams } \\
\text { terhadap Modal Sendiri } \\
\text { (RHJFTMS) }\end{array}$} & \multirow{5}{*}{$\begin{array}{l}\text { RHJPTMS tidak } \\
\text { melebiki } S 0 \%\end{array}$} & RHJPTMS $\leq 50 \%$ & 5 \\
\hline & & & $50 \%=$ RHIFTMS $\leq 65 \%$ & 4 \\
\hline & & & $65 \% \leq$ RHJPTMS $\leq 85 \%$ & 3 \\
\hline & & & $85 \%=\mathrm{RHJPTMS} \leq 100 \%$ & 2 \\
\hline & & & RHJPTMS $=100 \%$ & 1 \\
\hline \multirow{5}{*}{8} & \multirow{5}{*}{$\begin{array}{l}\text { Rasio Harta Lamcar terładap } \\
\text { Hutang Lancar (RHLTHL) }\end{array}$} & \multirow{5}{*}{$\begin{array}{l}\text { RHLTHI } \\
\text { mencapai 1,s }\end{array}$} & RHLTHI $\equiv 1,5$ & 5 \\
\hline & & & $1,35 \leq$ RHLTHL $\leq 1,5$ & 4 \\
\hline & & & $1,17 \subseteq$ RHLTHL $\leq 1,35$ & 3 \\
\hline & & & $1 \leq \mathrm{FHLTHL}=1,17$ & 2 \\
\hline & & & RHL THI $\leq 1$ & 1 \\
\hline \multirow{5}{*}{9} & \multirow{5}{*}{$\begin{array}{l}\text { Rasio Penjualan Bersik } \\
\text { terhadap Harta (RPETH) }\end{array}$} & \multirow{5}{*}{$\begin{array}{l}\text { RPBTH } \\
\text { mencapai } 18 \%\end{array}$} & $\mathrm{RPBT} \equiv 18 \%$ & 5 \\
\hline & & & $13 \% \leq$ FPET $\leq 18 \%$ & 4 \\
\hline & & & $9 \% \leq \mathrm{RPBT}=13 \%$ & 3 \\
\hline & & & $5 \% \leq$ RPET $\leq 9 \%$ & 2 \\
\hline & & & RPBT $\leq 5 \%$ & 1 \\
\hline \multirow{5}{*}{10} & \multirow{5}{*}{$\begin{array}{l}\text { Jangka Waktu Penagikan } \\
\text { Pintang (JWPP) }\end{array}$} & \multirow{5}{*}{$\begin{array}{l}\text { JWPP tidak } \\
\text { melebili } 45 \text { hari }\end{array}$} & JWPP $\leq 45$ & 5 \\
\hline & & & $45 \leq J W P P \leq 60$ & 4 \\
\hline & & & $60 \leq J W P P \leq 75$ & 3 \\
\hline & & & $75=$ JWPP $\leq 90$ & 2 \\
\hline & & & JWPP $=90$ & 1 \\
\hline \multirow{5}{*}{11} & \multirow{5}{*}{ Efeltivitas Penagikan (EP) } & \multirow{5}{*}{$\begin{array}{l}\text { EP mencapai } \\
81 \%\end{array}$} & $\mathrm{EP} \equiv 81 \%$ & 5 \\
\hline & & & $76 \% \leq \mathrm{EP} \leq 81 \%$ & 4 \\
\hline & & & $71 \% \leq \mathrm{EP} \leq 76 \%$ & 3 \\
\hline & & & $66 \% \leq \mathrm{EP} \leq 71 \%$ & $\overline{2}$ \\
\hline & & & EP $\leq 66 \%$ & 1 \\
\hline \multirow{5}{*}{12} & \multirow{5}{*}{ Perputaran Persediaan (PerP) } & \multirow{5}{*}{$\begin{array}{l}\text { PerP mencapai } \\
3 \mathrm{kali}\end{array}$} & PerP $\leq 3$ & 5 \\
\hline & & & $2,1 \leq \overline{P e r P} \leq 3$ & 4 \\
\hline & & & $1,2 \leq \operatorname{PerP} \leq 2,1$ & 3 \\
\hline & & & $0,3 \leq \operatorname{PexP}<1,2$ & 2 \\
\hline & & & PerP $\leq 0,3$ & 1 \\
\hline
\end{tabular}

Setelah target-target atau tolok ukur untuk setiap indikator ditetapkan, langkah selanjutnya adalah melakukan penilaian kinerja dengan cara membandingkan hasil pengukuran kinerja dengan tolok ukur tersebut. Penilaian kinerja ini tidak hanya dilakukan untuk masing-masing indikator saja, akan tetapi juga untuk perusahaan secara keseluruhan.
Penentuan interval untuk penilaian kinerja CV. RUI INTI secara keseluruhan adalah sebagai berikut:

$$
\begin{aligned}
& \text { Interval }=\frac{\text { Skor Tertinggi - Skor Terendah }}{\text { Jumlah Tingkat Skala }} \\
& \text { Interval }=\frac{(5-1)}{5}=0,8
\end{aligned}
$$

Uraian interval untuk penilaian kinerja CV. RUI INTI secara keseluruhan dapat dilihat pada Tabel 17.

Tabel 17. Interval Penentuan Nilai Kinerja CV.Rui Inti

\begin{tabular}{|c|rrr|}
\hline Nilai Kinerja & \multicolumn{3}{|c|}{ Irterval } \\
\hline Sangat Buruk & 1,000 & - & 1,799 \\
\hline Buruk & 1,000 & - & 2,599 \\
\hline Sedang & 2,600 & - & 3,399 \\
\hline Baik & 3,400 & - & 4,199 \\
\hline Sangat Baik & 4,200 & - & 5,000 \\
\hline
\end{tabular}


Hasil penilaian kinerja untuk setiap indikator dari masing-masing perspektif dapat dilihat pada Tabel 18.

Tabel 18. Skor penilaian indikator kinerja CV. RUI INTI untuk bulan Januari-Mei tahun 2012

\begin{tabular}{|c|c|c|c|c|c|c|}
\hline \multirow{2}{*}{ Mo. } & \multirow{2}{*}{ Uraian } & \multicolumn{5}{|c|}{ Bulan } \\
\hline & & Jan & Feb & Mar & Apr & Mei \\
\hline & PERSPEKTIF KEUANGAN & & & & & \\
\hline $\mathbf{A}$ & Profitabilitas & & & & & \\
\hline 1 & Marjin laba kotor $(\%)$ & 4 & 3 & 5 & 5 & 5 \\
\hline 2 & Rasio laba atas penjualan (\%) & 5 & 5 & 5 & 5 & 5 \\
\hline 3 & Rasio laba atas investasi dana (\%) & 5 & 3 & 4 & 4 & 4 \\
\hline 4 & Perturnbukan penjualan (\%) & & 1 & 1 & 5 & 1 \\
\hline 5 & Rasio laba atas modal sendiri (\%) & 5 & 4 & 4 & 5 & 4 \\
\hline B. & Solvabilitas & & & & & \\
\hline 6 & Rasio koutang terhadap harta (\%) & 5 & 5 & 5 & 5 & 5 \\
\hline 7 & $\begin{array}{l}\text { Rasio loutame jangka panjang terhadap } \\
\text { modal sendiri (\%) }\end{array}$ & 5 & 5 & 5 & 5 & 5 \\
\hline $\mathbf{C}$ & Lilouiditas leuangan & & & & & \\
\hline 8 & $\begin{array}{l}\text { Rasio harta lancar tenhadap hutang } \\
\text { lancax }\end{array}$ & 2 & 1 & 2 & 3 & 3 \\
\hline $\mathbf{D}$ & Efisiensipengplolaan haxta & & & & & \\
\hline 9 & Rasio perijualan bersik terhadap harta & 5 & 5 & 5 & 5 & 5 \\
\hline 10 & $\begin{array}{l}\text { Jangka waktu penagikan pintang } \\
\text { (hari) }\end{array}$ & 5 & 4 & 3 & 4 & 3 \\
\hline 11 & Efeltivitas penagikan (\%) & 5 & 1 & 1 & 1 & 1 \\
\hline 12 & Perputaran persediaan & 4 & 4 & 3 & 3 & 3 \\
\hline \multicolumn{2}{|c|}{ Skor KinerjaPerspelktif Keuangan Rata-rata } & 4,17 & 3,42 & 3,58 & 4,17 & 3,67 \\
\hline & PERSPEKTIF PELANGGAN & & & & & \\
\hline 1 & $\begin{array}{l}\text { Persertase penambahan pelangean } \\
\text { bann }\end{array}$ & & & 5 & 5 & 3 \\
\hline 2 & Persentase pelangean lama & & & 1 & 1 & 1 \\
\hline 3 & Rasio penjualan per pelaruggan & 4 & 3 & 2 & 2 & 2 \\
\hline \multicolumn{2}{|c|}{ Skor Kinerja PerspeltifPelanggan Rata-rata } & 4,00 & $3, \infty$ & 2,67 & 2,67 & 2,00 \\
\hline
\end{tabular}

Tabel 18. Skor penilaian indikator kinerja CV. Rui Inti untuk bulan Januari-Mei tahun 2012 (lanjutan)

\begin{tabular}{|c|c|c|c|c|c|c|}
\hline \multirow{2}{*}{ No. } & \multirow{2}{*}{ Uraian } & \multicolumn{5}{|c|}{ Bulan } \\
\hline & & Jan & Feb & Mar & Apr & Mei \\
\hline & $\begin{array}{l}\text { PERSPEKTIF PROSES BISNIS } \\
\text { INTERNAL }\end{array}$ & & & & & \\
\hline 1 & Produktivitas bahanbaku & 2 & 2 & 1 & 2 & 1 \\
\hline 2 & Persentase barang hilang (\%) & 1 & 3 & 3 & 3 & 2 \\
\hline 3 & Persentase barang kembali (\%) & 3 & 2 & 3 & 3 & 3 \\
\hline 4 & Kontirnitas Bahan Baku (\%) & 3 & 2 & 2 & 1 & 4 \\
\hline 5 & $\begin{array}{l}\text { Kuantitas pasokan bahan baku (krg } \\
\text { per hari) }\end{array}$ & 5 & 5 & 2 & 3 & 4 \\
\hline \multicolumn{2}{|c|}{$\begin{array}{l}\text { Skor Kinerja Perspeltif Proses Bisris } \\
\text { Irtemal Rata-rata }\end{array}$} & 2,8 & 2,8 & 2,6 & 2,2 & 2,8 \\
\hline & $\begin{array}{l}\text { PER SPEKTIF PER TUMBUHAN } \\
\text { DAN PEMB ELAJARAN }\end{array}$ & & & & & \\
\hline 1 & Tingkat perputaran karyawan & 5 & 5 & 3 & 5 & 5 \\
\hline 2 & Absensi karyawan & - & 4 & - & - & 5 \\
\hline 3 & Produktivitas karyawam produksi & 4 & 5 & 2 & 2 & 3 \\
\hline 4 & Produktivitas karyawan penjualan & 5 & 4 & 3 & 4 & 3 \\
\hline \multicolumn{2}{|c|}{$\begin{array}{l}\text { Skor Kinerja Perspeltif Perturnbuhan } \\
\text { dan Pembelajaram Rata-rata }\end{array}$} & 3,5 & 3,6 & $2, \infty$ & 2,75 & 3,2 \\
\hline \multicolumn{2}{|c|}{ Skor Kinerja CV.MAHKOTA Kesehuruhan } & 3,62 & 3,20 & 2,61 & 3,00 & 2,92 \\
\hline \multicolumn{2}{|c|}{ Nilai Kinerja CV.MAHKOTA Kesehuruhan } & Baik & Sedanz & Sedang & Sedang & Sedane \\
\hline
\end{tabular}


Langkah selanjutnya setelah penilaian kinerja CV. RUI INTI selesai dilakukan adalah membuat diagram sebab akibat, yang memperlihatkan hubungan kausalitas antar masingmasing indikator dalam berinteraksi dan berkontribusi untuk mencapai tujuan akhir yang diinginkan.

\section{Analisis SWOT}

Dalam melakukan analisis SWOT (Strength, Weakness, Opportunity, Threat), pihak perusahaan harus mampu memahami lingkungan eksternal dan internal perusahaan dengan baik. Dengan mengkombinasikan peluang dan ancaman dari faktor eksternal dengan kekuatan dan kelemahan dari faktor internal perusahaan, maka dapat diperoleh suatu rumusan strategi yang bisa diimplementasikan oleh pihak perusahaan dalam mencapai visi dan misinya.

Kombinasi dari faktor internal dan eksternal ini dipetakan ke dalam matrik SWOT dan digunakan sebagai pemicu untuk menghasilkan alternatif strategi bagi perbaikan kinerja perusahaan pada masa yang akan datang, yang dapat dilihat pada Tabel 19 .

Tabel 19. Matrik SWOT

\begin{tabular}{|c|c|c|}
\hline & Strength & Weakness \\
\hline & $\begin{array}{l}\text { 1. Bahan baku tidak tergantung } \\
\text { kepada perusahaan lain, sehingga } \\
\text { harga pokok penjualannya rendah. } \\
\text { 2. Rasio laba atas penjualan selalu } \\
\text { berada pada posisi sangat baik. } \\
\text { 3. Rasio laba atas modal sendiri } \\
\text { selalu berada di atas target yang } \\
\text { ditetapkan. } \\
\text { 4. Tingkat solvabilitas perusahaan } \\
\text { berada pada posisi sangat baik. } \\
\text { 5. Persentase penambahan pelanggan } \\
\text { baru berada di posisi sangat baik. } \\
\text { 6. Petugas bagian penjualan } \\
\text { memiliki kemampuan yang baik } \\
\text { dalam memberikan pelayanan } \\
\text { kepada pelanggan. } \\
\text { 7.CV. Rui Inti memiliki pengalaman } \\
\text { yang cukup } \\
\text { 8. Citra merek CV.Rui Inti telah } \\
\text { terkenal dikalangan pelanggan. } \\
\text { 9. Sumber daya manusia yang } \\
\text { potensial. }\end{array}$ & $\begin{array}{l}\text { 1.Angka pertumbuhan penjualan } \\
\text { umumnya bernilai negatif. } \\
\text { 2.Jangka waktu penagihan dan } \\
\text { efektivitas piutang belum sesuai } \\
\text { dengan target yang diharapkan. } \\
\text { 3.Persentase pelanggan lama masih } \\
\text { rendah. } \\
\text { 4. Rasio penjualan per pelanggan } \\
\text { kurang memuaskan. } \\
\text { 5.Persentase barang kembali yang } \\
\text { masih tinggi. } \\
\text { 6.Kontinuitas bahan baku setiap } \\
\text { harinya bervariasi. Kuantitas } \\
\text { bahan baku juga mengalami } \\
\text { penurunan. } \\
\text { 7.Perusahaan belum memiliki } \\
\text { perencanaan secara tertulis. } \\
\text { 8.Kurangnya pengembangan sumber } \\
\text { daya manusia, yang terlihat dari } \\
\text { minimnya pelatihan untuk para } \\
\text { karyawan. } \\
\text { 9.Kurangnya promosi dan iklan } \\
\text { untuk produk-produk CV. RUI } \\
\text { INTI }\end{array}$ \\
\hline Oppurtunity & $\begin{array}{c}\text { Strategi Maxi-maxi } \\
\text { (Strength/Oppurtunity) }\end{array}$ & $\begin{array}{c}\text { Strategi Mini-maxi } \\
\text { (Weakness/Oppurtunity) }\end{array}$ \\
\hline $\begin{array}{lr}\text { 1. Adanya } & \text { Program } \\
\text { Kemitraan dan Bina } \\
\text { Lingkungan } \\
\text { yang merupakan program }\end{array}$ & $\begin{array}{l}\text { 1.(S2,S3,S4,O1,O5) Meningkatkan } \\
\text { investasi dengan melakukan kerja } \\
\text { sama dengan BUMN yang telah } \\
\text { ditunjuk pemerintah untuk }\end{array}$ & $\begin{array}{l}\text { 1.(W1,O5) Membuka jaringan } \\
\text { pemasaran baru ke Jakarta. } \\
\text { 2.(W1,O3,O4) } \\
\text { showroom di dekat MIA dan }\end{array}$ \\
\hline
\end{tabular}




\begin{tabular}{|c|c|c|}
\hline $\begin{array}{l}\text { kemitraan antara BUMN } \\
\text { dengan Usaha Mikro } \\
\text { Kecil dan Menengah } \\
\text { (UMKM). } \\
\text { 2. Kegiatan pameran yang } \\
\text { diadakan di berbagai } \\
\text { tempat. } \\
\text { 3.Pesatnya } \\
\text { pengembangan proses } \\
\text { seperti pengoperasian } \\
\text { Bandara Internasional } \\
\text { Minangkabau (BIM) dan } \\
\text { pendirian pusat } \\
\text { perbelanjaan di kota } \\
\text { Padang. } \\
\text { 4.Program pengembangan } \\
\text { pariwisata Sumatera } \\
\text { Barat. } \\
\text { 5.Permintaan produk dari } \\
\text { pasar Jakarta. } \\
\text { 6. Masih bayak lahan } \\
\text { pertanian yang kosong di } \\
\text { kota Padang. }\end{array}$ & $\begin{array}{l}\text { melaksanakan PKBL. } \\
\text { 2.(S8,O2) Selalu mengikuti setiap } \\
\text { pameran yang diadakan, untuk } \\
\text { meningkatkan penjualan sekaligus } \\
\text { sebagai ajang promosi bagi } \\
\text { produk-produk CV. RUI INTI } \\
\text { COORPORATION. } \\
\text { 3.(S6,S7,S8,O3,O4) Meningkatkan } \\
\text { jumlah pelanggan dengan } \\
\text { meningkatkan kerja sama dengan } \\
\text { pusat-pusat perbelanjaan yang } \\
\text { baru. }\end{array}$ & $\begin{array}{l}\text { membuka jaringan pemasaran di } \\
\text { dekat-dekat tempat pariwisata. } \\
\text { 3.(W8,O1) Ikut serta dalam PKBL } \\
\text { untuk melakukan pelatihan kepada } \\
\text { para karyawan. } \\
\text { 4.(W6,W7,O6) Menjalin kerja sama } \\
\text { dengan pemilik lahan pertanian } \\
\text { untuk memasok bahan baku sesuai } \\
\text { kebutuhan serta menetapkan target } \\
\text { produksi. }\end{array}$ \\
\hline Threat & $\begin{array}{l}\text { Strategi Maxi-mini } \\
\text { (Strength/Threath) }\end{array}$ & $\begin{array}{l}\text { Strategi Mini-mini } \\
\text { (Weakness /Threath) }\end{array}$ \\
\hline $\begin{array}{lr}\text { 1. Kemudahan } & \text { dalam } \\
\text { memasuki } & \text { industri } \\
\text { makanan khas } \\
\text { Minangkabau r dapat } \\
\text { meningkatkan jumlah } \\
\text { pendatang baru. } \\
\text { 2. Persaingan di antara } \\
\text { sesama industri makanan } \\
\text { khas Minangkabau. } \\
\text { 3. Kenaikan harga bahan } \\
\text { bakar minyak. }\end{array}$ & $\begin{array}{l}\text { 1. (S5,S6,T1,T2)Meningkatkan } \\
\text { kualitas pelayanan terhadap } \\
\text { pelanggan, seperti pemberian } \\
\text { bonus, diskon atau merchandise } \\
\text { agar para pelanggan tetap aktif } \\
\text { dalam melakukan transaksi dan } \\
\text { tidak pindah ke pesaing. } \\
\text { 2.(S1,S7,T3) Meningkatkan } \\
\text { efisiensi penggunaan sumber daya } \\
\text { untuk menekan biaya.produksi. }\end{array}$ & $\begin{array}{l}\text { 1.(W3,W4,W5,T1,T2) } \\
\text { Meningkatkan kualitas produk } \\
\text { dengan menjaga kualitas bahan } \\
\text { baku yang digunakan. } \\
\text { 2. (W4,T2) } \\
\text { diversifikasi Meningkatkan } \\
\text { produk agar pilihan pelanggan } \\
\text { lebih bervariasi sehingga dapat } \\
\text { meningkatkan penjualan per } \\
\text { pelanggan) } \\
\text { 3. (W9,T1,T2) Melakukan promosi } \\
\text { dan iklan untuk meningkatkan } \\
\text { jumlah pelanggan r dan } \\
\text { meningkatkan citra perusahaan di } \\
\text { mata pelanggan. }\end{array}$ \\
\hline
\end{tabular}

\section{PENUTUP}

\section{Kesimpulan}

Dari penelitian yang dilakukan di CV.Rui Inti, dapat diambil kesimpulan sebagai berikut : Kinerja CV.Rui Inti pada bulan Januari berada pada predikat baik dengan skor 3,62. Akan tetapi pada bulan Februari sampai bulan Mei, kinerja perusahaan turun ke posisi sedang dengan skor bervariasi. Skor kinerja CV.Rui Inti untuk bulan Februari sampai dengan bulan Mei tahun 2012 masing-masing adalah 3,$20 ; 2,61 ; 3,00$; 2,92 . Jadi skor kinerja yang paling rendah terdapat pada bulan Maret yaitu sebesar 2,61, sedangkan yang paling tinggi terdapat pada bulan Januari yaitu sebesar 3,62.

Strategi yang diusulkan untuk diimplementasikan oleh CV. RUI INTI dikelompokkan ke dalam dua kelompok orientasi bisnis, yaitu strategi bertahan 
(defend) dan strategi berkembang (expand). Strategi pada kedua orientasi bisnis ini, memiliki fokus terhadap dua hal yaitu aspek pemasaran dan aspek produksi : Bertahan (defend), dengan usulan strategi seperti mengikuti setiap pameran yang diadakan, baik di dalam maupun di luar kota, meningkatkan kualitas pelayan terhadap para pelanggan untuk meningkatkan kepuasan pelanggan, meningkatkan efisiensi penggunaan sumber daya untuk menekan biaya produksi, mengikuti pelatihan yang diadakan Program Kemitraan dan Bina Lingkungan (PKBL) dan meningkatkan kualitas produk yang dihasilkan.

Berkembang (expand), dengan usulan strategi seperti meningkatkan investasi dengan melakukan kerja sama dengan BUMN yang ikut serta dalam PKBL, menjalin kerja sama dengan pusat-pusat perbelanjaan yang ada di Kota Enrekang maupun kota-kota lainnya untuk meningkatkan jumlah pelanggan baru, membuka jaringan distribusi baru ke daerah Jakarta, mendirikan fasilitas pemasaran baru di tempat-tempat strategis, menjalin kerja sama dengan para pemilik lahan pertanian di Kota Enrekang, untuk menambah pasokan bahan baku, meningkatkan diversifikasi produk agar pilihan pelanggan lebih bervariasi, melakukan aktivitas promosi dan iklan untuk meningkatkan citra perusahaan dan meningkatkan jumlah penjualan.

\section{Saran}

Hasil penelitian ini diharapkan dapat menjadi masukan bagi CV.Rui Inti dalam merumuskan strategi pencapaian visi dan misinya, untuk mencapai keuntungan yang bersifat jangka panjang. Beberapa hal yang perlu diperhatikan untuk penyempurnaan penelitian ini lebih lanjut adalah :

Penilaian kinerja ini perlu dilakukan secara berkala sehingga kenaikan atau penurunan kinerja segera dapat diketahui, dengan demikian bisa dilakukan perbaikan yang dibutuhkan. Oleh karena itu, data-data yang diperlukan untuk pengukuran kinerja ini agar dapat dipertahankan dan dilengkapi. Dan agar pengukuran kinerja dapat lebih mudah dilakukan, maka perlu dikembangkan suatu sistem informasi penilaian kinerja di CV. RUI INTI.

Untuk target-target yang telah dapat dicapai dengan mudah, sebaiknya ditingkatkan sehingga menantang untuk perbaikan kinerja perusahaan pada masa yang akan datang.

Untuk evaluasi yang berhubungan dengan pelanggan dan pemasaran, mungkin pengambilan periode tahunan akan lebih baik daripada bulanan. Sebab dalam periode tahunan, fluktuasi dan trend data akan lebih terlihat.

Pada penelitian ini tidak dilakukan pembobotan terhadap masingmasing indikator pada setiap perspektif, sehingga setiap indikator dianggap memberikan kontribusi yang sama dalam pencapaian kinerja. Untuk penelitian selanjutnya, hendaknya dilakukan pembobotan terhadap masingmasing indikator, untuk menggambarkan persentase pengaruh setiap indikator terhadap kinerja keseluruhan.

Produk CV. RUI INTI berfugsi sebagai oleh-oleh. Karena itu pengukuran kinerja pada musim liburan dan lebaran juga diperlukan karena hasilnya mungkin akan jauh berbeda dibandingkan periode pengukuran yang telah dilakukan saat ini.

\section{DAFTAR RUJUKAN}

Amaratunga, D, dkk. Assesment of Facilities Management Performance - What Next ?, MCB University Press, 2000. 
Artley, W. and Stroh, S. The Performance-Based Management Handbook : Establishing an Integrated Performance Measurement System, University of California, California, 2001.

Handoko, T. Hani. Manajemen Personalia dan Sumber Daya Manusia, BPFE-Yogyakarta, Yogyakarta, 2001.

Hayun, A. Pengukuran Kinerja dengan Model Compromize Performance Measurement System (CPMS) Sebagai Perbaikan Terhadap Model Balance Scorecard (BSC) dan Integrated Performance Measurement System (IPMS), Seminar Nasional Sains \& Teknologi, Yogyakarta, 2003.

Hitt, M.A, dkk. Manajemen Strategis : Daya Saing dan Globalisasi Konsep, Penerbit Salemba Empat, Jakarta, 2002.

Hopf, R.H, dkk. Guide to a Balance Scorecard Performance Management Methodology. Procurement Executives Association, 1997.

Kaplan, R. S. and Norton, D. P. Balanced Scorecard Menerapkan Strategi Menjadi $A k s i$, Penerbit Erlangga, Jakarta, 2000.

Milana. Penilaian kinerja untuk Perumusan Strategi Pencapaian Visi dan Misi PDAM Kota Padang, Tugas Akhir, Padang, 2004.
Nurmianto, Eko, dkk. Analisa Pengaruh Peningkatan Kinerja di Badan Pengelolaan Keuangan Kabupaten " $X$ " dengan Metode Analytical Hierarchy Process (AHP), Seminar Nasional Sains \& Teknologi Akprind, Yogyakarta, 2003.

Prawirosentono, Suyadi. Pengantar Bisnis Modern : Studi Kasus Indonesia dan Analisis Kuantitatif, Bumi Aksara, Jakarta, 2002.

Rangkuti, F. Measuring Customer Satisfaction : Teknik Megukur dan Strategi Meningkatkan Kepuasan Pelanggan, PT Gramedia Pustaka Utama, Jakarta, 2003.

Rangkuti, F. Business Plan : Teknik Membuat Perecanaan Bisnis dan Analisis Kasus, PT Gramedia Pustaka Utama, Jakarta, 2003.

Sutojo, S. Mengenali Arti dan Penggunaan Neraca Perusahaan, PT. Damar Mulia Pustaka, Jakarta, 2004.

Suwignyo, dkk. Performance Management Workshop, Universitas Surabaya, Surabaya, 2002.

Umar, H. Evaluasi Kinerja Perusahaan, PT. Gramedia Pustaka Utama, Jakarta, 2003.

.Business An Introduction, PT. Gramedia Pustaka Utama, 